\title{
Narrowing the Gap of Stroke Management between Developed and Developing Countries: Report of the Fifth International Stroke Summit, Nanjing, China, July 17-19, 2009
}

\author{
Gelin Xu Qin Yin Xinfeng Liu \\ Department of Neurology, Jinling Hospital, Nanjing University School of Medicine, Nanjing, China
}

Stroke is a geographically heterogeneous disease, with morbidity and mortality varying significantly among countries and regions [1]. Socioeconomic development is a major determinant for these discrepancies [2]. Poverty has been associated with increased risk for and unfavorable outcome after stroke [3]. In less developed countries such as China, stroke incidence and recurrence are higher due to the low control rate of modifiable risk factors for cardiovascular diseases [4]. Stroke patients in these countries are younger, which consequently leads to more healthy years of life lost. Patients are more likely to lose their chance of timelimited treatments such as thrombolysis due to a lack of proper infrastructure, unawareness of warning signs and delay of transportation [5]. The proportions of patients being treated in a stroke unit with integrated multidisciplinary care are smaller. As a result, stroke has a more malignant prognosis and induces a heavier socioeconomic burden in these countries.

To narrow the gap of stroke management between developed and developing countries, the World Stroke Organization (WSO) has initiated a serial of regional meetings and educational programs in recent years. The International Stroke Summit is one of these activities endorsed by the WSO to promote stroke prevention and treatment in China. This annual conference has been successfully convened for 5 times since 2004. According to the organizing plan, the scientific committee suggests a main topic for next summit and announces it in the closing ceremony of the previous summit. The first summit was held in Beijing in September 2004. Epidemiology and prevention of stroke was the main topic, and more than 2,000 researchers and doctors participated in the Beijing meeting [6]. The second summit was held in Nanjing in August 2006, with in-hospital management of acute stroke as the main topic [7]. The third summit was held in Wuhan in November 2007, with prehospital management and posthospital rehabilitation of stroke as the main topic $[8,9]$. The fourth summit was held in Nanjing in July 2008, with endovascular solutions for stroke prevention and treatment as the main topic $[10,11]$.

The fifth international stroke summit was held in July 17-19, 2009 in Nanjing. Following the proposal of the WSO, narrowing the gap of stroke prevention and management between developed and developing countries was recommended as the main topic of this year's summit. Participants were encouraged to discuss differences in stroke etiology, subtypes, incidence, recurrence, risk factors, diagnosis, prevention, management and prognosis among countries and regions. Special emphasis was put on generalizing stroke education, increasing awareness of stroke warning signs among average people, improving prehospital transportation and increasing the control rates of modifiable risk factors.

The fifth international stroke summit was co-chaired by Xinfeng Liu from Jinling Hospital, Nanjing University School of Medicine, China and Natan Bornstein from Sourasky Medical Center, Tel Aviv University, Israel. Prof. Natan Bornstein, vice president of the WSO, made an opening address on behalf of the WSO, and Prof. Xueming Yi, president of Jinling Hospital, made an opening address on behalf of the organizers. Prof. Bornstein expressed greetings from the WSO to the participants. He introduced a brief history of the WSO, which was formed in October 29, 2006 after the merger of the International Stroke Society and the World Stroke Federation. The WSO is a nongovernmental organization and is officially related to the World Health Organization. The concept is that stroke needs to be presented by a single voice with a broad-based representation. One mission of the WSO is to change the face of stroke education by launching a serial of new projects, such as founding the World Stroke Academy and organizing local and regional meetings. Prof. Bornstein said the WSO will be a resource center providing information about stroke for health professionals, medical doctors and public to improve stroke management on a global scale. The WSO proposed that October 29 in each year be the World Stroke Day, a day with a message for every day: stroke is a treatable and a preventable catastrophe. The theme of the World Stroke Day in 2009 is: 'Stroke; what can I do?' Prof. Bornstein also praised the contribution of the International Stroke Summit. He encouraged the organizers to continue their efforts in improving stroke management in developing countries such as China. Prof. Xueming Yi expressed his benedictions to the conference. He reviewed the initiation and development of the International Stroke Summit. He said this annual stroke summit always follows innovation and gives guidance to clinics. It has become

\section{KARGER}

Fax +41613061234 E-Mail karger@karger.ch www.karger.com
(C) 2009 S. Karger AG, Base $1015-9770 / 10 / 0291-0101 \$ 26.00 / 0$

Accessible online at: www.karger.com/ced
Xinfeng Liu

Department of Neurology, Jinling Hospital

305 Zhongshan East Road, Nanjing University School of Medicine

Nanjing 21002 (China)

Tel. +86 258527 2631, Fax +86 258480 1861, E-Mail xfliu2@yahoo.com.cn 
one of the highest-level academic events in China, and its influence will continuously enhance in the years to come.

Xinfeng Liu introduced the status of stroke prevention and treatment in China. As the most populous country, China has the largest number of stroke victims in the world. The unbalanced socioeconomic development and miscellaneous lifestyles lead to a wide discrepancy in stroke incidence, prevalence and recurrence among regions and populations. The incidence of stroke in China ranged from 81 to 450 per 100,000 among 30 provinces in mainland China, with the highest incidence in underdeveloped west and north regions. Incidence and prevalence of stroke have increased continuously in many parts of China as a result of population aging and lifestyle transition in recent years. Stroke etiology in China is not consistent with that in western populations. The proportion of stroke caused by large-artery atherosclerosis, especially intracranial atherosclerotic disease, is higher in Chinese patients than in western patients. The first-year mortality and recurrence are relatively higher in Chinese patients with large-artery atherosclerosis. Considering these profiles, strategies of stroke prevention and management made for Chinese patients should put sufficient emphasis on large-artery atherosclerosis treatment. Dr. Liu also introduced different statuses of carotid endarterectomy and angioplasty and carotid artery stenting in treating atherosclerotic carotid diseases. Due to a shortage of skilled neurosurgeons, carotid endarterectomy is not available in most Chinese hospitals. Carotid artery stenting has developed rapidly in recent years and has become an alternative for treating carotid stenosis where carotid endarterectomy is not available.

Natan Bornstein from Tel Aviv University delivered a lecture concerning diagnosis and treatment of vascular dementia. He reported that more than $20 \%$ of stroke patients develop dementia. This makes stroke an important risk factor for dementia. Bornstein emphasized the differences and similarities of vascular dementia and dementia of Alzheimer disease. He said most patients with dementia have dual pathologies, ischemic and neurodegenerative. Even if one predominates, this does not mean the other is unimportant or does not contribute to the cognitive loss.

Gelin Xu from Nanjing University School of Medicine introduced the Nanjing Stroke Registry Program (NSRP). The NSRP is the first stroke registry program launched in mainland China. It has registered 3,000 cases of first-ever stroke since 2003. All registered patients had been followed up regularly. The baseline and follow-up data are managed with a tailored computer software. Using data from the NSRP, Xu and colleagues have studied the case mortality and recurrence of stroke in Chinese patients, which have never been reported.

Ming Liu from West China University compared the guidelines for stroke management of China, Europe and the USA. She emphasized the importance of evidence-based medicine in guiding the practice of stroke management. But she also suggested that socioeconomic development and cultural background should be considered when making the guidelines for populations in developing countries such as China. Some techniques or medicines with proved efficacy may not be available or affordable to the mass population.

Laszlo Miskolczi from the University of Miami introduced biomechanical considerations for intracranial stenting. With the accumulation of intracranial stenting cases, several technical problems have been reported, which include intimal hyperplasia (in-stent restenosis), stent migration, stent fracture, uneven deployment of stent struts and perforation of artery. These technical pitfalls may result in severe complications. There are various intracranial stents available with different biomechanical features. Dr. Miskolczi reviewed the biomechanical features of the available stents and gave his suggestions on how to select stents for patients with different profiles of the artery to be treated and access.

Yinghua Zou from Beijing University introduced the complications after carotid stenting. He also shared his experiences on how to prevent and manage cerebral hyperperfusion syndrome after carotid stenting. Zou said patients with severe carotid stenosis, bilateral stenosis and absence of efficient collaterals bear an increased risk for post-stenting hyperperfusion syndrome. To decrease their risk of hyperperfusion syndrome, surveillance and control of blood pressure is very important.

About 1,000 doctors and physicians from China and other countries participated in the meeting, and many others watched this summit via the internet live translation. In the closing ceremony, the organizers announced that the next meeting, the sixth international stroke summit, will be held on July 9-11, 2010 in Nanjing, China. Thirty selected abstracts submitted to the conference were published in Cerebrovascular Disease [12]. Detailed information concerning the conference is available on the website: www.stroke.net.cn.

\section{References}

1 Howard VJ, Cushman M, Pulley L, Gomez CR, Go RC, Prineas RJ, Graham A, Moy CS, Howard G: The reasons for geographic and racial differences in stroke study: objectives and design. Neuroepidemiology 2005;25: 135-143.

-2 Donnan GA, Fisher M, Macleod M, Davis SM: Stroke. Lancet 2008;371:1612-1623.

$\checkmark 3$ Lopez AD, Mathers CD, Ezzati M, Jamison DT, Murray CJ: Global and regional burden of disease and risk factors, 2001: systematic analysis of population health data. Lancet 2006;367:1747-1757.

4 Xu G, Liu X, Wu W, Zhang R, Yin Q: Recurrence after ischemic stroke in Chinese patients: impact of uncontrolled modifiable risk factors. Cerebrovasc Dis 2007;23:117-120.
5 Durai Pandian J, Padma V, Vijaya P, Sylaja PN, Murthy JM: Stroke and thrombolysis in developing countries. Int J Stroke 2007;2:1726.

6 Selected abstracts for the ISS Regional Cerebrovascular Diseases Conference. Cerebrovasc Dis 2004; 18:352-378.

7 Selected abstracts for the Second International Stroke Summit. Cerebrovasc Dis 2006; 22:318-329.

$>8$ Selected abstracts for the Third International Stroke Summit. Cerebrovasc Dis 2007; 24:483-494.
9 Xu G: Building a platform for East-West communication in stroke research: report of the Third International Stroke Summit, Wuhan, China, November 1-3, 2007. Cerebrovasc Dis 2008;25:279-280.

$>10$ Selected abstracts for the Fourth International Stroke Summit. Cerebrovasc Dis 2008; 26:212-222.

11 Xu G, Cheng S, Liu X: Focus on endovascular solutions for cerebrovascular diseases: report of the Fourth International Stroke Summit, Nanjing, China, July 25-27, 2008. Cerebrovasc Dis 2008;26:667-668.

12 Selected abstracts for the Fifth International Stroke Summit. Cerebrovasc Dis 2009; 28:209-219. 